\title{
Наталья Бесецкая
}

- Полоцкий государственный университет

- e-mail: n.besetskaya@psu.by

- ORCID: 0000-0002-2167-1917

\author{
ОСОБЕННОСТИ ПРАВОВОГО РЕГУЛИРОВАНИЯ МЕДИАЦИИ \\ В БЕЛАРУСИ И ПОЛЬШЕ: СРАВНИТЕЛЬНО-ПРАВОВОЙ АСПЕКТ \\ THE FEATURES LEGAL REGULATION OF MEDIATION \\ IN BELARUS AND POLAND: A COMPARATIVE LEGAL ASPECT
}

\section{Abstract}

- Goal - this article's main goal is to provide the differences in the legal regulation of mediation in the Belarusian and Polish legislation, taking into account the identification of comparable comparison criteria, and on their basis to determine the possibility of borrowing of certain rules.

- Research methodology - the author focuses on the application of comparative jurisprudence as a comparative method of cognition of mediation, in general, and its method of normative comparison by formal legal analysis, in particular. This allowed to identify the unique, typical, general and special in the legal regulation of mediation in the legislation of Belarus and Poland.

- Score/results - the article includes several sections where based on comparison of Belarusian and Polish legislation the most essential aspects of mediation institution are disclosed: sources of legal regulation; the field and grounds of mediation application; issues of conclusion and execution of mediation agreement. As a result, the trends of legal regulation of the institution of mediation in Belarus and Poland are revealed.

- Originality/value - the article is the first comparative legal study of the legislation of Belarus and Poland on mediation, has theoretical and practical significance, and contains author's generalizations and conclusions.

| Key words: alternative dispute resolution, agreement to use mediation, comparative law, conflict, dispute, mediation, mediator, mediation agreement. 


\section{1. Введение}

Медиация в современном мире - одна из наиболее востребованных форм альтернативного разрешения споров (далее: APC). Однако в большинстве государств институциональную форму и нормативное закрепление она приобрела не сразу. Ее появление - своеобразный ответ гражданского общества на неспособность государственной системы правосудия предоставить адекватную судебную защиту. С этой проблемой изначально столкнулись страны с состязательной системой судопроизводства, где перегруженность судов породила негативные последствия. Активное развитие форм АРС, по сути, стало «маркером» уровня демократизации общества. Постепенно акцент с необходимости снижения нагрузки на государственные суды в качестве первопричины развития института медиации стал смещаться, и на первый план вышли очевидные ее преимущества по сравнению с государственным правосудием. Тем не менее отсутствие адекватного законодательного регулирования медиации становится одним из факторов, сдерживающих ее активное развитие. Так, в докладе Комиссии Европейского парламента необходимость законодательного регулирования медиации обосновывается стремлением создать «предсказуемые правовые рамки» для потенциальных сторон спора [Report..., 2016: 11]. Этому процессу в большинстве стран предшествовал период накопления практического опыта применения медиации, которая, являясь частной инициативой, фактически находилась вне правового поля и не подлежала регламентации.

Вместе с тем институализация медиации в государствах осуществляется по-разному ${ }^{1}$. Этот процесс охватил и страны бывшего Советского Союза. В Республике Беларусь в 2013 году был принят специальный закон [Zakon..., 2013]. При этом предполагалось, что его принятие усилит развитие медиации, однако опыт его реализации в течение последних шести лет демонстрирует обратное. В Польше судебная процедура посредничества появилась еще в 2005 году с принятием закона о внесении поправок в Гражданский процессуальный кодекс (далее: ГПК Польши) [Ustawa..., 1964].

Географическая близость Беларуси и Польши, сходное правовое наследие, вовлеченность в интеграционные процессы и возрастающая роль медиации в урегулировании широкого круга правовых и неправовых конфликтов

${ }^{1}$ О моделях правового режима медиации см. Eliseev, 2013: 19. 
представляют интерес для сравнительного правоведения, так как внедрение форм АРC не должно осуществляться без анализа иностранного опыта, а также учета национального менталитета.

В настоящей статье на основе выделения сопоставимых критериев сравнения выявляются различия в правовом регулировании медиации в белорусском и польском законодательстве, и, учитывая ее объем, автор основное внимание сосредотачивает на анализе нормативных правовых актов по наиболее существенным аспектам медиации.

\section{2. Источники правового регулирования медиации}

В 1995 году в Польше была создана Рабочая группа по внедрению медиации, на базе которой в последующем образовался Польский центр медиации. В 1997 году медиация была введена в Уголовный кодекс [Wróbel, 2007], а внесение изменений в 2005 году в ГПК Польши позволило применять ее и по гражданским спорам, в том числе коммерческим, семейным и трудовым. Кроме того, правовое закрепление получили основания медиации, требования к медиатору, принципы медиации, правила о вознаграждении медиаторов, требования к содержанию ходатайства о медиации, условия, при которых суды могут передавать дело на медиацию, а также ее процедура. В 2016 году вступил в силу Закон о внесудебном разрешении потребительских споров, разработанный в целях реализации Директивы 2013/91/EU [Ustawa..., 2016]. В нем определены обязанности субъектов, уполномоченных вести внесудебное производство по разрешению потребительских споров, порядок ведения реестра таких лиц, принципы процедуры. Нормы о медиации включены также в Уголовно-процессуальный кодекс, Уголовно-исполнительньй кодекс, Кодекс административного судопроизводства и в Закон о производстве по делам несовершеннолетних. Министерством юстиции Польши, помимо этого, регулируются вопросы, касающиеся расчета расходов на проведение медиации и ее стоимости, размера вознаграждения посредника, порядка ведения списка постоянных посредников и др.

Внедрение института медиации в Беларуси началось с «пилотного проекта» развития внесудебной медиации как средства урегулирования хозяйственных и иных споров, инициированного Высшим Хозяйственным Судом Республики Беларусь и проведенного при его поддержке в 2011-2012 годах. 
Его успешность стала толчком к разработке специального закона о медиации. Действующий закон регулирует сферу применения медиации, ее принципы, требования к медиатору, порядок организации его деятельности, основания применения медиации, правила проведения медиации, основания ее прекращения, требования к медиативному соглашению и его исполнение [Zakon..., 2013]. Параллельно были изменены Гражданский процессуальный кодекс, Хозяйственный процессуальный кодекс (далее: ГПК, ХПК). В развитие указанного закона Совет Министров и Министерство юстиции определили: процедуру медиации; порядок создания и деятельности Квалификационной комиссии по вопросам медиации, выдачи и прекращения действия свидетельства медиатора; типовые правила деятельности организации, обеспечивающей проведение медиации; правила этики медиаторов; подготовку медиаторов и др.

Практика применения на протяжении 5 лет Закона о медиации выявила ряд сфер, где применение медиации могло быть расширено. Помимо отмеченного, сложности обуславливаются и сохраняющимися различиями в регулирования судебной медиации в гражданском и хозяйственном процессах. C 1 июля 2020 года в Республике Беларусь начнет действовать Закон от 18 декабря 2019 г. № 277-3 [Zakon..., 2019], который вносит изменения в Гражданский кодекс, Кодекс о браке и семъе, ГПК и ХПК, Налоговьй кодекс и Закон о медиации. Реформирование законодательства направлено на повышение популярности медиации и снижение нагрузки судов общей юрисдикции, унификацию положений о медиации в процессуальном законодательстве. Эффективность этого еще предстоит выяснить, но таким образом законодатель стремиться преодолеть особенности национальной ментальности - воспринимать все новое с осторожностью и недоверием. Вместе с тем достижение указанной цели возможно только через комплексное решение существующих проблем, а это, на наш взгляд, в новом законе до конца не удалось достигнуть.

\section{3. Сфера применения медиации}

В польском законодательстве более широко определен круг дел, по которым возможно применение медиации. Так, статья 10 ГПК Польши предусматривает возможность медиации по любому делу [Ustawa..., 1964]. Кроме того, в законодательстве прямо не исключается возможность посредничества 
по налоговым, таможенным или административным вопросам или в связи с ответственностью государства за действия или бездействие при осуществлении государственной власти [Study for an evaluation..., 2016: 35]. Согласно § 1 статьи 23а Уголовно-процессуального кодекса судья или судебный референдар, а в ходе подготовительного производства прокурор или другой ведущий процесс орган могут по инициативе или с согласия обвиняемого и потерпевшей стороны передать дело учреждению или лицу, уполномоченному на это, с целью проведения медиации между потерпевшей стороной и обвиняемым [Ustawa..., 1997]. В административном судопроизводстве участником процедуры медиации может выступать и орган, проводящий разбирательство [Ustawa..., 1960].

В пункте 1 статьи 2 Закона о медиации в Республике Беларусь определено, что медиация применяется для разрешения споров, возникающих из гражданских правоотношений, в том числе хозяйственных, трудовых, семейных и других [Zakon..., 2013]. Несмотря на то, что в пункте 3 статьи 2 указывается на его распространение не только на гражданское и хозяйственное судопроизводство, но и на иные виды судопроизводства в случаях, предусмотренных законодательными актами, «рамочный» характер закона делает формально и фактически невозможным применение медиации по уголовным, административным конфликтам. Данная норма остается декларативной, поскольку в законодательстве нет прямых норм об этом. В 20142015 годах в Палату представителей Национального собрания Республики Беларусь последовательно подавались два проекта закона о внесении изменений и дополнений в Уголовный и Уголовно-процессуальный кодексы. В них предлагалось проведение медиации по преступлениям, которые относятся к делам частного обвинения и возбуждаются лицом, пострадавшим от преступления путем подачи заявления в суд. Однако принятие подобного закона было признано несвоевременным. Аналогичная проблема существует и применительно к спорам, возникающим из публичных правоотношений (пункт 5 статья 2 Закона о медиации).

В обеих странах законодательство не устанавливает конкретный перечень категорий споров, передаваемых в медиацию. Однако из-за «размытости» действующих формулировок на практике в Беларуси возникли сложности с их толкованием. Например, несмотря на указание в пункте 1 статьи 2 Закона о медиации возможности проведения медиации по трудовым спорам, в отличие от польского законодательства, нельзя урегулировать таким образом коллективные трудовые споры, так как в трудовом 
законодательстве для них устанавливаются специальные внесудебные формы: примирительная комиссия, посредничество ${ }^{2}$ и трудовой арбитраж. В тоже время и в отношении индивидуальных трудовых споров медиация возможна, если они не касаются применения законодательства о труде, коллективного договора, соглашения. Как справедливо отмечает В.С. Каменков, не допускается медиация по таким спорам работников - членов профсоюза, а также по их спорам, касающихся применения локальных правовых актов и трудовых договоров [Kamenkov, 2014]. При этом комиссия по трудовым спорам, созданная нанимателем на паритетных началах с представителями профсоюза, является обязательным первичным органом их разрешения. В случае нарушения такого внесудебного порядка суд откажет в возбуждении производства по делу. Однако переход в медиацию возможен ${ }^{3}$ в случаях, когда подобная комиссия не создана, либо спор не связан с применением законодательства о труде, коллективного договора, соглашения, либо работник не является членом профсоюза либо спор инициируется нанимателем. Рассмотренные коллизии мог бы устранить новый закон ${ }^{4}$, однако в нем не предусмотрено изменение положений Трудового кодекса.

Кроме того, в белорусском законодательстве присутствуют и «косвенные» ограничения. В частности, в пункте 1 статьи 2 Закона о медиации не упоминается об урегулировании «любых» споров, возникающих из гражданских правоотношений, трудовых и семейных правоотношений, напротив, иное может быть установлено законодательными актами или вытекать из существа соответствующих отношений [Zakon..., 2013]. Полагаем, такой подход позволяет изымать из сферы применения медиации довольно широкий круг споров и допускает высокую степень «усмотрения» юрисдикционных органов. Так, например, в ХПК установлен открытый перечень категорий дел, связанных с осуществлением предпринимательской и иной хозяйственной (экономической) деятельности, отнесенных к исключительной подведомственности экономических судов.

\footnotetext{
${ }^{2}$ Не следует путать с медиацией. Статус посредника, порядок проведения посредничества по коллективным трудовым спорам не подпадают под действие Закона о медиации и регулируются только трудовым законодательством.

${ }^{3}$ Мы разделяем мнение В.С. Каменкова.

${ }^{4}$ Имеется ввиду Закон Республики Беларусь «Об изменении законов» от 18 декабря 2019 № 277-3.
} 
В доктрине ${ }^{5}$ предпринимались попытки предложить критерии медиабельности 6 споров, однако единообразного подхода ни к их количеству, ни к их качественному наполнению так и не выработано.

При этом возникает своеобразный парадокс, поскольку белорусское законодательство не содержит указания на последствия урегулирования спора в медиации, изъятого из сферы ее применения. Вместе с тем не исключено расширительное толкование судами основания ${ }^{7}$ отказа выдаче исполнительного документа на принудительное исполнение медиативного соглашения по мотиву его несоответствия требованиям процессуального законодательства о мировом соглашении.

\section{4. Основания применения медиации}

В ГПК Польши предусмотрено два правовых основания применения: заключение сторонами соглашения о медиации либо постановление суда, предписывающее сторонам участвовать в медиации [Ustawa..., 1964]. При этом в польской доктрине указывает на существование трех видов медиации по способу ее инициирования: договорная медиация; медиация, инициированная одной из сторон в ходе судебного разбирательства или до его начала; судебная медиация [Zinkevich, 2014]. Согласно § 3 статьи 183-1 ГПК Польшu в соглашении о медиации стороны должны указать предмет медиации, медиатора или способ его избрания. Оно может быть заключено и путем направления одной стороной запроса при отсутствии возражения стороной стороны. В запросе нужно указать наименование сторон, обстоятельства, обосновывающие требование, подпись и опись прилагаемых документов. Инициирование медиации судом является его правом, которое он может реализовать на любой стадии разбирательства. При этом до первого заседания, назначенного для проведения слушаний, он определяет необходимость направления сторон в медиацию. Если стороны не дали согласия на проведение медиации в течение недели с даты объявления или вручения им постановления суда, она не проводится. Отсюда вытекает, что стороны

${ }^{5}$ О критериях медиабельности споров см. подробнее: Chichina 2017.

${ }^{6}$ Под «медиабельностью» понимается способность конфликтов и споров быть урегулированными посредством медиации.

${ }^{7}$ Нормы о принудительном исполнении медиативного соглашения с 1 июля 2020 года будут унифицированы в процессуальных кодексах, см. Zakon..., 2019. 
должны вести себя активно, иначе медиация не состоится. В Польше возможна информационная встреча, посвященная методам мирного урегулирования споров, в том числе медиации, проводимая судьей, судебным референдаром, судебным секретарем, помощником судьи или постоянным посредником. Стимулом к ее посещению является право суда обязать неявившуюся сторону возместить все расходы, понесенные другой стороной в связи с явкой в суд [Ustawa..., 1964].

В Беларуси основания применения медиации до суда или вне зависимости от обращения в суд устанавливает Закон о медиации. При переходе в медиацию из суда следует также учитывать положения процессуального законодательства. Юридическим фактом, допускающим урегулирование спора в медиации, в любом случае является соглашение о применении медиации. В соответствии с пунктом 1 статьи 20 Закона о медиации оно должно быть заключено в письменной форме ${ }^{8}$. Его могут заключить физические лица, обладающие полной дееспособностью, и (или) юридические лица. В нем должно быть предусмотрено: указание споров, подлежащих урегулированию в медиации, сведения о медиаторе (медиаторах) и их вознаграждении, сроке и месте проведения медиации [Zakon..., 2013]. При этом его заключение не лишает его стороны права обратиться с иском в суд. После обращения истца в суд медиация может быть проведена по гражданскому делу на любой стадии судебного разбирательства, а по экономическому - только до начала рассмотрения дела по существу. Однако Закон 2019 года создаст условия для унификации положений о медиации в обоих процессах, поскольку с 1 июля 2020 года спор может быть передан в медиацию по письменному соглашению сторон до удаления суда в совещательную комнату для вынесения судебного постановления по существу спора. Экономический суд будет вправе это сделать и с согласия сторон по собственной инициативе. Изменения коснутся и последствий заключения соглашения о применении медиации. Так, по гражданскому делу появится альтернатива: не только обязательное приостановление судом производства, но и по совместному ходатайству сторон оставление заявления без рассмотрения [Zakon..., 2019]. В экономическом суде передача спора в медиацию влечет оставление искового заявления без рассмотрения [ХПК 1998].

\footnotetext{
${ }^{8}$ Как в виде отдельного документа, путем обмена документами между сторонами, так и посредством включения медиативной оговорки в текст договора.
} 
В отличие от хозяйственного процесса, в гражданском процессе передача спора в медиацию возможна не только в суде первой инстанции, но и апелляционной инстанции [ГПК, 1999]. Это связано с тем, что в ХПК реализована квазисудебная процедура, являющаяся разновидностью судебной медиации, - примирительная процедура ${ }^{9}$. Примиритель может быть назначен в суде первой, апелляционной, кассационной инстанций по ходатайству одной или обеих сторон либо по инициативе суда. Стороны в течение семи дней с момента вынесения определения судом вправе представить возражения. Логично предположить, что закон расценивает молчание сторон в такой ситуации как согласие. Тем не менее это не лишает сторон права в любой момент выйти из примирительной процедуры. При назначении примирительной процедуре экономический суд вправе приостановить производство по делу. Принципиальным отличием от внесудебной медиации является возможность назначения примирителем лиц, занимающих государственную должность в суде, и иных лиц на договорной основе, обладающих квалификацией по существу конфликта, список которых ведет Пленум Верховного Суда [ХПК, 1998].

В мировой практике не существует универсального подхода к тому, должна ли быть медиация обязательной ${ }^{10}$. В Польше как договорная, так и судебная медиация носит добровольный характер. Тем не менее в 2008 году предпринималась попытка ввести обязательную медиацию по семейным спорам ${ }^{11}$. Аналогичным был подход и в Беларуси. Однако с 1 июля 2020 года обязательной медиация станет по спорам между юридическими лицами и (или) индивидуальными предпринимателями до обращения с иском в экономический суд [Zakon..., 2019]. Насколько эта мера повлияет на активизацию применения медиации в Беларуси, покажет время.

\section{5. Порядок заключения и исполнения медиативного соглашения}

Термин «медиативное соглашение» в польском законодательстве отсутствует, но он вполне сопоставим с термином «соглашение об урегулировании,

\footnotetext{
${ }^{9}$ О примирительной процедуре подробнее см. в главе 17 ХПК от 15 декабря 1998 № 219-3, [электронный ресурс] http://www.pravo.by/document/?guid = 3871\&p0 = НК9900238 [дата доступа: 15.01.2020].

${ }^{10}$ См. подороднее: 'Rebooting' the mediation..., 2014.

11 Там же, с. 50.
} 
достигнутое перед медиатором» (ugoda zawarta przed mediatorem). В гражданских делах, если стороны достигли урегулирования, медиативное соглашение вносится в протокол или прилагается к нему. Посредник информирует стороны, что подписание медиативного соглашения обусловливает их согласие представить его в суд на утверждение. Суд оперативно проводит разбирательство для утверждения медиативного соглашения. И отказывает его утвердить или заявить о его вступлении в силу, полностью или частично, если оно противоречит закону, противоречит морали, направлено на обход закона, вводит в заблуждение или содержит противоречия, нарушающие законные интересы стороны. Согласованное с судом медиативное соглашение, признанное мировым соглашением и вступившее в законную силу, может быть исполнено [Ustawa..., 1964]. По уголовным делам и делам несовершеннолетних мировое соглашение, достигнутое в ходе медиации, не заменяет судебное решение и не является обязательным для суда, однако он обязан соблюдать считаться с ним по окончании разбирательства [Ustawa..., 1997].

По итогам внесудебной медиации в Беларуси заключается медиативное соглашение, а в примирительной процедуре - соглашение о примирении. По сути, они оба - медиативные соглашения, однако между ними есть несколько принципиальных отличий. Так, соглашение о примирении может быть заключено только в пределах заявленных требований истцом. Его утверждение и исполнение производятся судом так же, как и мировое соглашение [ХПК, 1998]. Медиативное соглашение заключается в письменной форме, и должно содержать сведения о сторонах, медиаторе, предмете спора, принятых сторонами обязательствах и сроках их выполнения. Оно подписывается сторонами, медиатором и не должно противоречить требованиям законодательства и нарушать права третьих лиц [Zakon..., 2013].

По общему правилу, медиативное соглашение должно быть исполнено самими сторонами в силу принципов добровольности и добросовестности. Последствия неисполнения медиативного соглашения могут быть установлены сторонами в медиативном соглашении. Однако если стороны предусмотрят санкции (штрафы, пени и т. п.), то принудительно исполнить медиативное соглашение будет невозможно, в силу противоречия требованиям процессуального законодательства о мировых соглашениях. Принудительно не исполняются также медиативные соглашения, не утвержденные судом в качестве мировых соглашений и (или) заключенные с участием медиатора, не внесенного в Реестр медиаторов. 
Таким образом, для принудительного исполнения заинтересованная сторона должна подать по гражданскому делу заявление об утверждении мирового соглашения, отказе истца от иска, о признании иска ответчиком [ГПК, 1999]. В экономическом суде существует специальная процедура ${ }^{12}$, возбуждаемая по заявлению о выдаче исполнительного документа на принудительное исполнение медиативного соглашения, подаваемого в течение шести месяцев со дня окончания срока добровольного исполнения. Оно рассматривается с извещением сторон в судебном заседании в месячный срок. По результатам суд выносит определение и выдает исполнительный документ либо отказывает в этом [ХПК, 1998]. За рассмотрение данного заявления взимается государственная пошлина (на сегодняшний день примерно 100 евро, для физических лиц с 1 июля 2020 года она составит около 20 евро), в отличие от польского законодательства, где подобная пошлина не уплачивается, если медиация проводилась на основании постановления суда или утверждается медиативное соглашение по договорной медиации.

\section{6. Выводы}

Таким образом, в обоих государствах реализована модель детализированного регулирования медиации. Однако польское законодательство о медиации децентрализовано и нормы рассредоточены в различных нормативных правовых актах (как процессуального, так и материального права). Полагаем, в белорусском законодательстве избран более фундаментальный подход, который позволяет в одном нормативном правовом акте установить общие положения о медиации в целом как формы APC независимо от категории споров. При этом и объем регулирования, на наш взгляд, в Беларуси более значительный. С одной стороны, это вызвано особенностями национального менталитета (гражданам гораздо «спокойнее» применять что-то «новое» на основании правовых норм), с другой - демонстрирует желание государства сохранять контроль данной сферы гражданского общества, сделать прозрачными последствия применения рассматриваемой формы АРС.

В польском законодательстве сфера применения медиации определяется значительно шире. Возможность провести медиацию практически по

12 C 1 июля 2020 года аналогичный порядок вводится и по гражданским делам, см. Zakon..., 2019. 
любому гражданскому делу, а также по предусмотренным в законе уголовным и иным делам из публичных отношений создает большую степень свободы участникам конфликта. Белорусскому же законодателю только предстоит двигаться в данном направлении, и изучение опыта Польши может оказать неоценимую помощь. Кроме того, отсутствие критериев медиабельности споров в отечественном законодательстве, сохранение «косвенных» ограничений - сдерживающие факторы развития медиации в Республике Беларусь. Потенциальным пользователям медиации, полагаем, должны быть адресованы более прозрачные, ясные и понятные нормы о сфере ее применения.

И в Беларуси, и в Польше возможно проведение медиации как до, так и после обращения в суд. И, несмотря на различие терминологии, в отношении оснований применения медиации предусмотрены сходные правила. Однако в судебной медиации разное значение придается молчанию сторон (в Беларуси оно трактуется как согласие на ее проведение, а в Польше, как их возражение).

Сравнение положений о медиативном соглашении позволяет заключить, что в польском законодательстве определены более четкие основания отказа в его принудительном исполнении, более простой порядок утверждения, а также импонирует избирательный подход к установлению платы за придание ему исполнительно силы или выдачу исполнительного документа. Полагаем, это является более продуктивным с точки зрения стимулирования к более активному использованию медиации для урегулирования споров.

\section{Ілитература}

Chichina E.V., 2017, Pravovye kriterii mediabelnosti sporov po zakonodatelstvu Respubliki Belarus, «Pravo.by», No. 2 ||Чичина Е.В., 2017, Правовые критерии медиабельности споров по законодательству Республики Беларусь, «Право.ьу», № 2.

Eliseev D.B., 2013, Rol mediacii v razreshenii pravovykh konfliktov: teoretiko-pravovoj analiz, avtoreferat dissertacii ... kandidata yuridicheskikh nauk: 12.00.01, Moskva || Елисеев Д.Б., 2013, Роль медиации в разрешении правовых конфликтов: теоретико-правовой анализ, автореферат диссетации ... кандидата юридических наук: 12.00.01, Москва.

GPK, 1999: Grazhdanskij processualnyj kodeks Respubliki Belarus ot 11 yanvarya 1999 г. No. 238-Z || ГПК, 1999: Гражданский процессуальный кодекс Республики Бела- 
русь от 11 января 1999, № 238-3, [электронный ресурс] http://www.pravo.by/ document/?guid = 3871\&p0 = НК9900238 [дата доступа: 15.01.2020].

HРК, 1998: Hozyajstvennyj processualnyj kodeks Respubliki Belarus ot 15 dekabrya 1998 No. 219-Z || ХПК, 1998: Хозяйственный процессуальный кодекс Республики Беларусь от 15 декабря 1998 № 219-3, [электронный ресурс] http:// www.pravo.by/document/?guid $=3871 \&$ p0 $=$ НК9900238 [дата доступа: 15.01.2020].

Kamenkov V.S., 2014, Vozmozhnost mediacii po individualnym trudovym sporam, Minsk || Каменков В.С., 2014, Возможность медиации по индивидуальным трудовым спорам, Минск.

'Rebooting' the mediation directive: Assessing the Limited Impact of its Implementation and Proposing Measures to increase the Number of Mediations in the EU, 2014, [electronic resource] http://www.europarl.europa.eu/thinktank/en/document.html?reference $=$ IPOL-JURI_ET(2014)493042 [date of access: 10.02.2020].

Report from the Commission to The European Parliament, the Council and The European Economic and Social Committee on the application of Directive 2008/52/EC of the European Parliament and of the Council on certain aspects of mediation in civil and commercial matters, COM/2016/0542 final, Brussels, 26.8.2016, [electronic resource] https://op.europa.eu/en/publication-detail/-/publication/234da71d-6ebb-11 e6-b076-01aa75ed71a1 [date of access: 1.02.2020].

Study for an evaluation and implementation of Directive 2008/52/EC - the 'Mediation Directive', final report, 2016, [electronic resource] https://op.europa.eu/en/ publication-detail?p_p_id = portal2012documentDetailActions_WAR_portal2012portlet_INSTANCE_P7Lc96wTRLvv\&p_p_lifecycle $=2 \&$ p_p_state $=$ maximized\&p_p_cacheability = cacheLevelPage\&p_p_col_id $=$ secontent\&p_p_col_ count $=2 \&$ cellarId $=6 c 84$ b6a6-913e-4231-a677-55f8fa9ccbb6\&requestAction $=$ rdf [date of access: 1.02 .2020 ].

Ustawa z dnia 14 czerwca 1960 r. Kodeks postępowania administracyjnego (Dz.U. z 2016 r., poz. 23, z późn. zm.) (wyciąg z przepisów), [online] https://www. gov.pl/attachment/da64ca3c-8fc2-43ed-b169-90c54803aaeb [data dostępu: 1.02.2020].

Ustawa z dnia 17 listopada 1964 r. Kodeks postępowania cywilnego (Dz.U. z 2016 r., poz. 1822, z późn. zm.) (wyciąg z przepisów), [online] https://www.gov.pl/ attachment/0c4304f4-ff9f-4346-a62c-0088024b8364 [data dostępu: 1.02.2020].

Ustawa z dnia 6 czerwca 1997 r. Kodeks postępowania karnego (Dz.U. z 2016 poz. 1749) (wyciąg z przepisów), [online] https://www.gov.pl/attachment/88d4b564-b4ea47e1-a5ec-57d08e6042a4 [data dostępu: 1.02.2020].

Ustawa z dnia 10 września 2015 r. o zmianie niektórych ustaw w związku ze wspieraniem polubownych metod rozwiązywania sporów (Dz.U. 2015, poz. 1595).

Ustawa z dnia 23 września 2016 r. o pozasądowym rozwiązywaniu sporów konsumenckich (Dz.U. z 2016 r., poz. 1823), [online] https://www.gov.pl/ attachment/11fae684-424f-4fe2-811e-876d433940f7 [data dostępu: 1.02.2020]. 
Wróbel A.M., 2007 Mediation In Poland, [online] https://www.mediate.com//articles/ wrobelA2.cfm [data dostępu: 10.02.2020].

Zakon Respubliki Belarus “O mediacii” ot 12 iyulya 2013 No. 58-Z || Закон Республики Беларусь «О медиациџ» от 12 июля 2013 № 58-3, [электронный ресурс] http://www.pravo.by/document/?guid $=3871 \&$ p0 $=$ h11300058 [дата доступа: 15.01.2020].

Zakon Respubliki Belarus “Ob izmenenii zakonov” ot 18 dekabrya 2019 No. 277-Z || Закон Республики Беларусь «Об изменении законов» от 18 декабря 2019 № 277-3, [электронный ресурс] http://www.pravo.by/upload/docs/op/ H11900277_1577480400.pdf [дата доступа: 15.01.2020].

Zinkevich A.Z., 2014, Mediaciya v Polshe, "Lex Russica”, No. 4 || Зинкевич А.3., 2014, Медиация в Польше, «Lex Russica», № 4. 